\title{
Failure Analysis at the Kennedy Space Center
}

\author{
Victoria L. Salazar and M. Clara Wright ${ }^{*}$ \\ National Aeronautics and Space Administration, Kennedy Space Center, FL, 32899
}

\begin{abstract}
History has shown that failures occur in every engineering endeavor, and what we learn from those failures contributes to the knowledge base to safely complete future missions. The necessity of failure analysis is at its apex at the end of one aged program and at the beginning of a new and untested program. The information that we gain through failure analysis corrects the deficiencies in the current vehicle to make the next generation of vehicles more efficient and safe. The Failure Analysis and Materials Evaluation Branch in the Materials Science Division at the Kennedy Space Center performs metallurgical, mechanical, electrical, and non-metallic materials failure analyses and accident investigations on both flight hardware and ground support equipment for the Space Shuttle, International Space Station, Constellation, and Launch Services Programs. This paper will explore a variety of failure case studies at the Kennedy Space Center and the lessons learned that can be applied in future programs.
\end{abstract}

\section{Introduction}

TAILURE analysis at the Kennedy Space Center (KSC) is performed on both flight hardware and ground support - equipment for all of the programs that operate at the center. The failures analyzed by the Materials Science Division include metallurgical, mechanical, electrical, and non-metallic materials failures. The fundamental goal of the analysis is to determine the root cause of the failure in order to prevent future failures. The majority of failures can typically be attributed to one or more of the following causes: failure due to fabrication problems; failure due to environmental problems; failure due to maintenance and processing problems; and failure due to design problems.

The proper fabrication of hardware is of fundamental importance to the success of the component. Several failures have been analyzed where a part has received an inadequate heat treatment, improper coating, or unauthorized material substitution. The failures that occur due to fabrication problems typically become evident early in the materials evaluation. Whereas many problems can be prevented through a quality assurance program, some problems are not apparent until failure occurs under service conditions.

The location of KSC is an impetus for failure due to corrosion and other environmental problems. The combination of the salt from the Atlantic Ocean along with the heat, humidity, and sunlight has resulted in the Beach Corrosion Test Site at KSC to be documented as the most corrosive test site in the United States ${ }^{1}$. In addition to the natural environment, the chemical propulsion used in the Space Shuttle solid rocket boosters results in hydrochloric acid deposition onto launch structures and ground support equipment, which accelerates the rate of corrosion at the launch pads.

Subjecting components to their design-intended loads and maintaining these components properly can be a challenge at KSC. The service requirements of some of the components and structures are beyond those seen anywhere else in the world, and the work cannot be done in a clean room environment. Whether a refractory material that must withstand the blast of a launch, or a crawler transporter that carries a twelve-million pound vehicle assembly and mobile launcher platform to the launch pad, the proper maintenance of the components is vital to ensuring mission success.

The design of a component is a critical factor in its success throughout the lifetime of the part. Most components will ultimately perform their designed functions. However, the design process may sometimes fail to take into account certain factors, such as accessibility for maintenance and inspection, which can eventually lead to failure. Additionally, over a 30 year program, modifications to the original design can lead to unintended consequences that result in failure.

The failures that occur at KSC are typically a combination of the presented factors with the factor of age playing a large role. The Space Shuttle program is now almost 30 years old, and much of the flight hardware and ground support equipment are original to the program. Additionally, some of the ground support equipment that was used

\footnotetext{
* Materials Engineer, Materials Failure Analysis Laboratory, Mail Code: NE-L1-M.

1

American Institute of Aeronautics and Astronautics
} 
during the Apollo program is currently in use today. KSC has been directed to update the launch infrastructure, which could present different sources of failure. By studying historical failures and learning the lessons that they present, NASA can have a higher rate of mission success in future programs.

\section{Case Studies}

\section{A. Failure Due to Fabrication Problems ${ }^{2}$}

International Space Station (ISS) materials and processes engineering personnel submitted a payload canister rail from the Rotation Handling Fixture when a crack was observed on the top of the rail during installation. The Rotation Handling Fixture is used to lift the modules of the ISS into a vacuum chamber in order to perform leak checks. The drawing specified that the rail be composed of AISI 4140 steel (UNS G41400). Fig. 1 shows the payload canister rail, as received. The blue arrows indicate the six notches that are cut into the top of the rail in order to fit a thrust block assembly used to secure the payload to the rail. The yellow arrow indicates the location of the crack (inset). Two apparent weld repairs were observed in the locations indicated by the red arrows. The distance between the weld repair regions and their closest notches was approximately equal to the distant between adjacent notches, which is equal to $10 \mathrm{~cm}$. The rail was sectioned longitudinally in order to remove the top ledge from the base of the rail so that examination of the underside of the ledge could be performed. Four cracked regions were

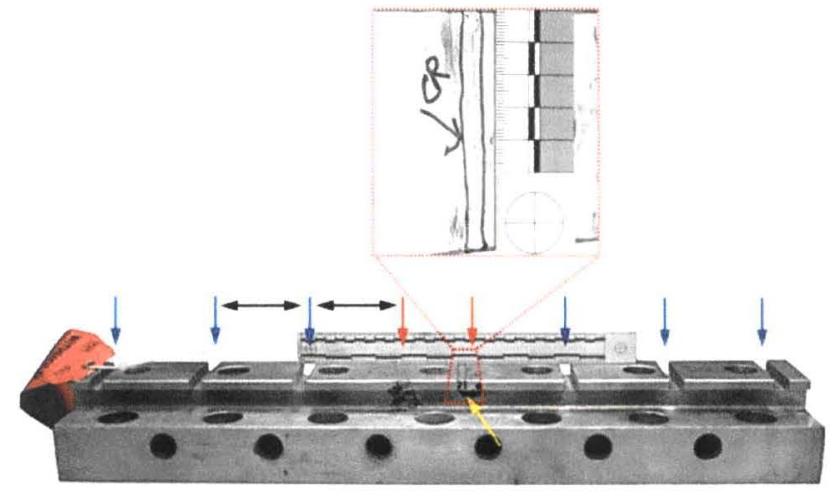

Figure 1. Payload canister rail, as received, with an inset image of the crack on the top of the rail. Scales are in $\mathrm{cm}$ increments. observed on the underside of the ledge near the weld repair regions.

The crack was opened using an Instron tensile tester in a three-point bend loading configuration in order to examine the fracture surface. Corrosion product covered the majority of the revealed surfaces, as shown in Fig. 2. The corrosion product was removed in order to reveal the features on the surface. The surfaces were flat and only

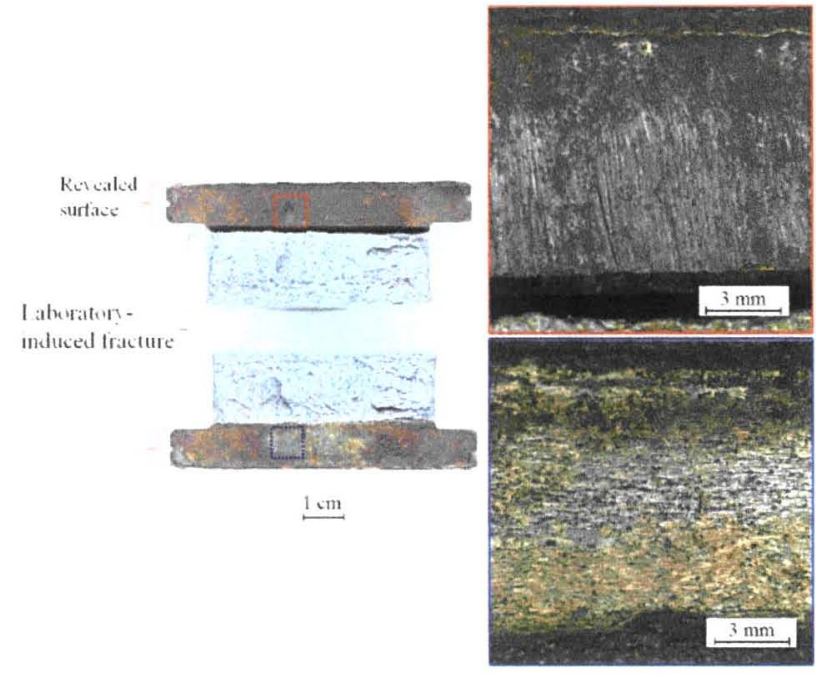

Figure 2. Stereomicroscope images of the revealed service fracture. had a small region of fracture around the edge of the surface that was approximately 1 to $2 \mathrm{~mm}$ wide. Plating was observed on one of the revealed surfaces (Fig. 2, bottom right). The other surface displayed tools marks that appeared to be the result of a machining and grinding operation (Fig. 2, top right).

Analysis of the fracture surface via scanning electron microscope (SEM) revealed tool marks on both of the surfaces. Examination of the fracture region around the edge of both of the surfaces revealed dimples formed by microvoid coalescence (MVC), characteristic of ductile stress overload. Analysis of the bulk metal surface with qualitative/semi-quantitative energy dispersive spectroscopy via the SEM (SEM/EDS) confirmed the presence of nickel plating on one of the revealed surfaces.

Metallographic specimens were prepared from cross sections of the unfractured weld repair region. Initial observation of the metallographic specimens after etching indicated that a piece of different material was welded into a notch cut in the base material and that the weld had penetrated less than $3 \mathrm{~mm}$, as shown in Fig. 3 . The size of the notch correlated with the size of the machined notches that were located in six positions on the rail in order to install the thrust block. On the underside of the rail ledge, the weld did not fuse the fill piece with the base metal. 
Metallographic specimens were also prepared from cross-sections of the fractured weld region. Macroscopic examination of the metallographic specimens indicated that cold-work lines parallel to the fracture surface were present on the fill material, which would indicate that the bar was cut from a larger plate of material and the material was inserted such that the transverse cross-section was sustaining the load. Metallographic analysis of the samples confirmed the stereomicroscope and SEM findings that plating was present on the bulk metal surface and the fracture surface was limited to a small region on the edge of the specimen. The weld used to hold the piece of fill materials in the notch also had significant porosity.

Microscopic examination of the bulk metal metallographic specimen indicated that the base microstructure was ferrite and pearlite dendrites. The heat-affected zone (HAZ) had a progressive microstructure of ferrite and

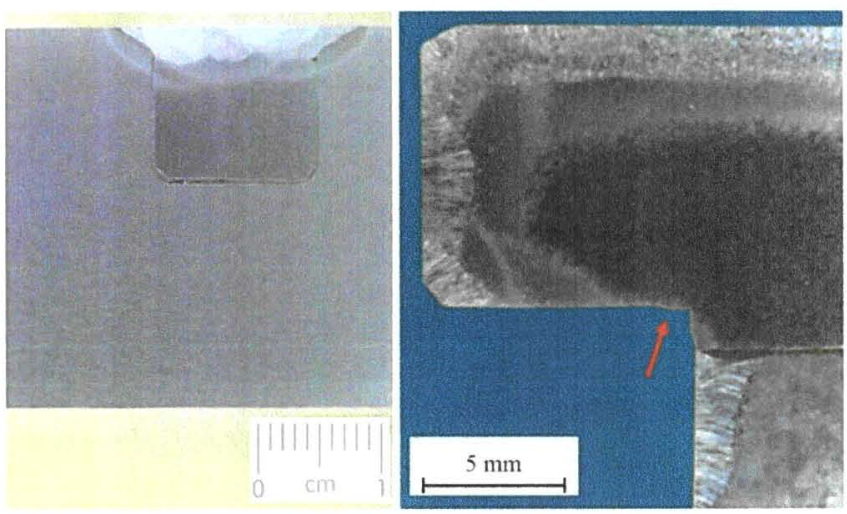

Figure 3. Cross-sections of the weld repair region showing a piece of metal inserted into the rail (left) with an incomplete weld around the edge (right, arrow). untempered martensite and plate martensite showing the prior austenite grain boundaries. The fusion zone structure was ferrite with martensite/austenite/carbides (MAC). The microstructures found in the bulk metal were typical for a 4140 steel weld.

Microscopic examination of the fill material metallographic specimens revealed that the base microstructure was coarse grain ferrite and pearlite. The HAZ had a progressive microstructure of spheroidized pearlite in ferrite, ferrite and martensite in refined prior austenite grain boundaries, and ferrite and martensite in coarse prior austenite grain boundaries. The fusion zone structure was ferrite with MAC. The microstructures found in the fill material were typical for welded plain carbon steel.

Microhardness measurements were taken on the metallographic specimens prepared from the cross-sections of the fracture surface and were converted ${ }^{3}$ to the Rockwell B scale (HRB). The converted hardness of the bulk metal averaged $92 \mathrm{HRB}$. The converted hardness of the fill metal averaged $82 \mathrm{HRB}$, which is significantly less than the hardness of the bulk rail metal. The hardness of the bulk metal from the rail met the drawing requirements; however, the hardness of the fill metal was less than the required hardness of the rail.

Chemical analysis determined that the bulk metal was AISI 4140 steel (UNS G41400), which was in accordance with the drawing. The fill material was determined to likely be a 1000 -series steel and most closely matched AISI 1030 steel (UNS G10300).

The payload canister rail failed due to improper fabrication techniques. The rail had two cut notches that were not in accordance with the drawing, and thereby were filled with a low-strength, 1000-series steel. The grinding marks on the fill material surface indicate that the cut piece of materials was ground in order to fit into the miscut notch. The weld around the steel bar that was used to fill the slot did not have adequate penetration to fuse the fill material with the bulk rail metal. The lack of fusion was the most pronounced on the underside of the rail and acted as crack initiation points. The rail subsequently failed due to stress overload.

\section{B. Failure Due to Environment Problems ${ }^{4}$}

Sections of wire rope that had been used as lightning protection at the launch pads were submitted for damage inspection to determine potential future usage of similar wire rope for future programs. The samples were pulltested as part of a separate investigation, and were subsequently submitted for evaluation of any service damage. The wire rope was reportedly type 316 stainless steel (UNS S31600), 6x19 right regular lay, with a 7x7 independent wire rope core (IWRC), installed in 2001 and removed in 2008.

Portions of the wire rope were photographed both in the field prior to pull testing and as received after pull testing. The majority of the ropes fractured at the swage fittings that were used to loop the wire ropes for pull testing. The fitting acted as a stress concentration due to the clamping of the fitting onto the wire rope. However, one sample fractured during pull testing at a damaged location on the wire rope and not at the swage fitting location. Visual observation of the wire rope revealed damage that was due to two separate environmental problems: corrosion and possible lightning damage. 


\section{Damage due to lightning}

Several areas of damage were observed on the surface of the wire rope that were apparent localized melted and

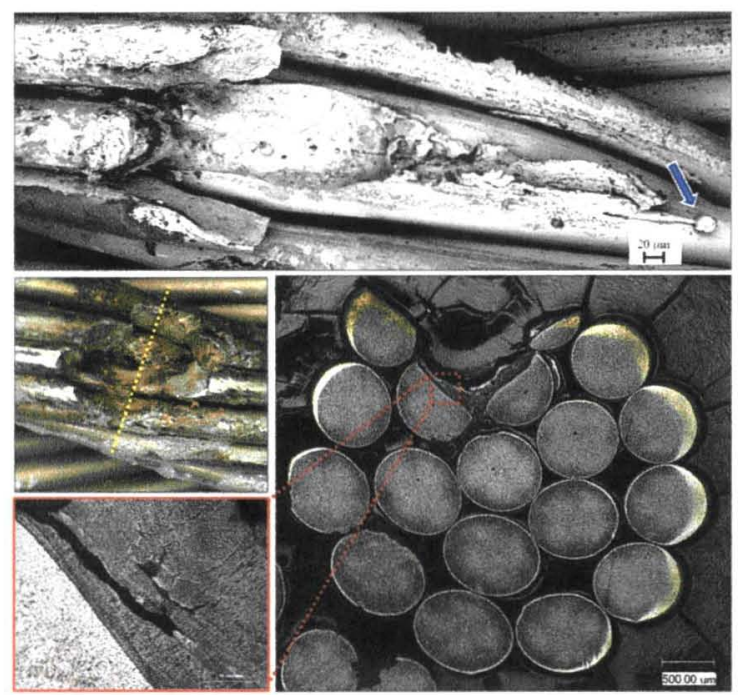

Figure 4. SEM image (top) and cross-section (bottom) of the wire rope. fused wires. Orange corrosion product was observed on the wire rope in the areas of the melting damage. The one pull test sample that did not fail at the swage fitting failed at one of the areas of apparent melting damage. SEM examination of one of these areas of damage observed via stereomicroscope revealed a melted bead of metal that formed during a localized heating event, as shown in Fig. 4 (blue arrow).

One of the areas of apparent melting and resolidification was cross sectioned and prepared for metallographic examination, as shown in Fig. 4 (yellow line). Observation of the cross-section indicated that five of the nineteen wires in the strand were damaged. The area of interest had a typical weld-like dendritic microstructure, confirming that the material had been melted and resolidified, as illustrated in Fig. 4 (red inset image). The base metal consisted of extremely fine austenitic grains in the transverse direction. The etchant preferentially reacted with the melted and resolidified metal, indicating that it is more prone to chemical attack than the original wire rope material, as confirmed through the observation of corrosion product in these damaged areas.

Microhardness measurements were taken on the wire rope cross-section. No significant hardness difference was noted in the wires near the damaged areas as compared to the rest of the wires, which indicates that the heat affected zone of the damaged area was very small.

\section{Damage due to corrosion}

Visual and stereomicroscopic inspection of the fractured wires in one of the ropes revealed pitting of the interior of several of the wires, as shown in the top left image in Fig. 5. Approximately one quarter of the wires in one strand had reduced cross-sectional areas due to the pitting. SEM observation of these wire indicated that the pitting was not limited to the exterior of the wires, and in some cases, the corrosion process preferentially attacked the interior of the wires, leading to a wormhole-like appearance.

The pitted wire sample was analyzed using EDS via the SEM. Spherical deposits containing aluminum and chlorine were observed within the pit, as shown in Fig. 5 (circled), which are typical of solid rocket booster (SRB) combustion product deposit. The corrosion product consisted primarily of oxygen, iron, and chromium with minor amounts of both chlorine and sulfur. The corrosion was likely due to chloride-induced pitting of the stainless steel wire from the chlorine-containing SRB deposition and from the marine environment.

One of the pitted wires was mounted and metallographically prepared to observe the longitudinal cross-section of the wire. Approximately two-thirds of the interior portion of the cross-section was pitted, as shown

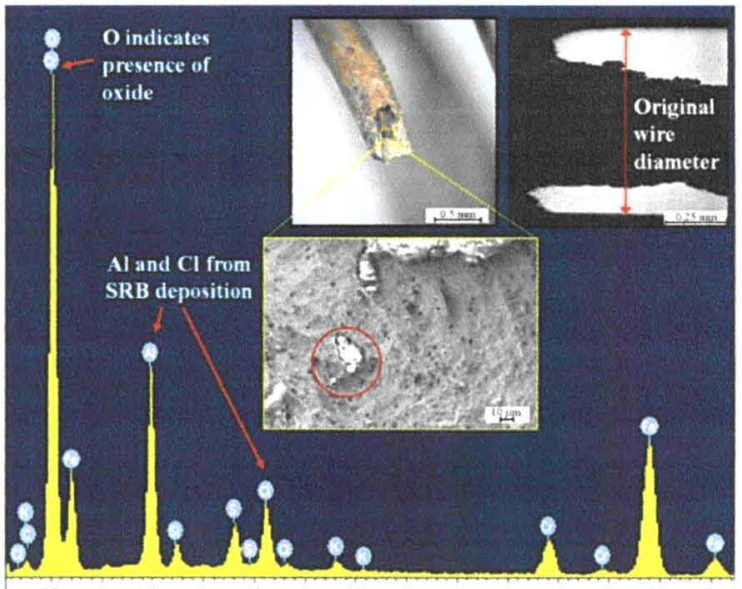

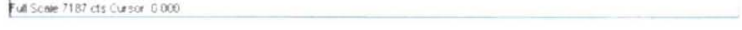

Figure 5. The pits observed via stereomicroscope (top left) were determined via SEM (bottom image) and EDS (spectrum) to contain SRB deposition (circled). The cross-section of the wire was reduced due to pitting (top right). in the top right image in Fig. 5. The grain structure of the wire was extremely elongated due to cold-working. The 
grain boundary attack caused the wormhole-like pitting of the interior of the wire since the corrosion mechanism acted longitudinally with the grain structure. In other words, the directionality of the grains due to cold working influenced the directionality of the pitting process, leading to wormhole-like pitting of the wire.

The metallurgical evaluation of the wire rope used at the launch pad as part of the lightning protection system for eight years revealed localized damage due to two different environmental factors. The localized nature of the damage in both cases would likely not affect the overall strength of the wire rope because only one quarter of the wires in one of the strands was damaged. Inspection of the wire rope would reveal the lightning strike damage areas because they occur on the surface of the wire rope; however, the pitting of the interior of the wires would be more difficult to detect through visual inspection.

\section{Failure Due to Processing and Maintenance Problems ${ }^{5}$}

A spherical bearing from a steering cylinder of the crawler transporter (CT) was submitted for failure analysis when a crack was observed during maintenance. The crawler transporter is used to transport the shuttle transportation system to the launch pad after mating operations in the Vehicle Assembly Building (VAB). The spherical bearing assumes the horizontal load during the steering of one of the four individual truck assemblies. The drawing specifies that the spherical bearing be composed of AISI E 52100 bearing steel (UNS G52986). Fig. 6 shows the location of the steering cylinder (blue arrow) and the
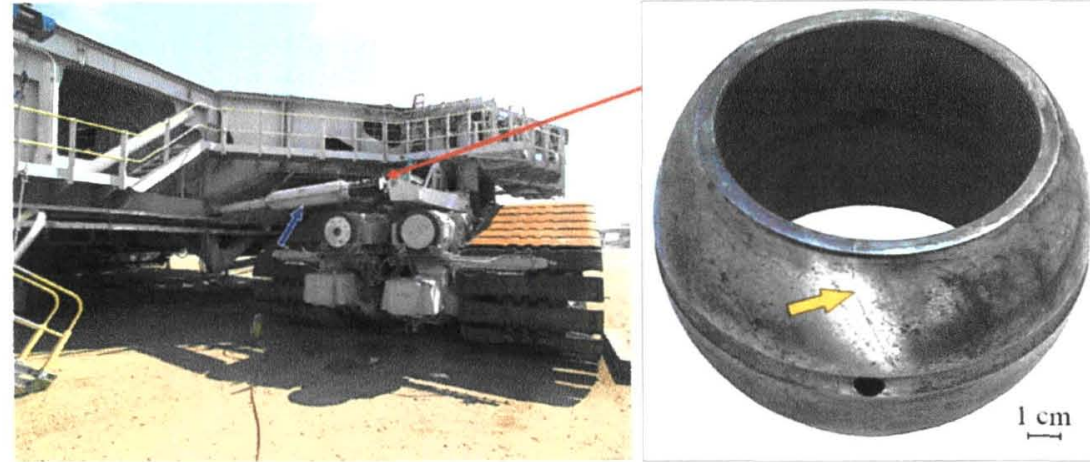

Figure 6. Image of the CT in the storage field (left) showing the steering cylinder (blue arrow) and the location of the cracked bearing (red arrow). The crack was observed on the surface of the spherical bearing (right, yellow arrow). location of the cracked bearing (red arrow).

The bearing was photographed as-received to document the location of the crack on the bearing, as shown in Fig. 6. A lubrication groove was located around the circumference of the spherical bearing. The bearing was submitted for nondestructive evaluation (NDE) by liquid penetrant and magnetic particle examination in order to extent of the

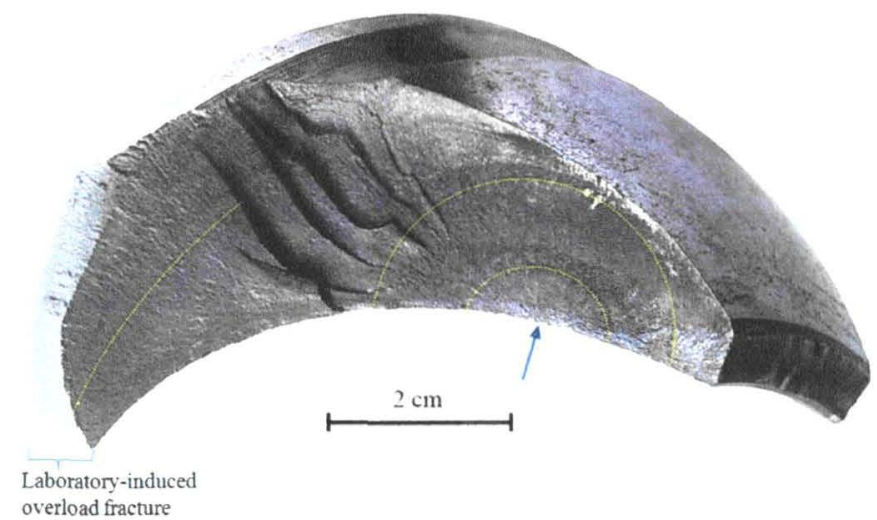

Figure 7. The revealed fracture surface displayed crack arrest marks (yellow lines). cracking. The crack tip was located just below the lubrication groove. A witness mark was observed on the interior surface of the spherical bearing, directly across from the location of the crack. The witness mark was more pronounced on the lower portion of the spherical bearing, indicating that uneven pressure was applied to the spherical bearing.

The spherical bearing was sectioned and the crack was opened in order to reveal the service fracture surface. The fracture surface was coated with grease and had a burnt odor when it was opened, evidence that the bearing was in operation subsequent to crack formation. The fracture surface was cleaned ultrasonically and visually examined and the fracture surface displayed conchoidal crack-arrest lines that indicate that the failure was progressive, as shown in Fig. 7. The blue arrow indicates the location of the origin, which was located on the weak axis of the spherical bearing.

Analysis of the fracture surface via SEM revealed mainly intergranular fracture features with localized areas of microvoid coalescence (MVC). The fracture surface also had smeared regions and corrosion product, which are further indications that the bearing was in service subsequent to fracture. Qualitative/semi-quantitative EDS

$$
5
$$


analysis via the SEM indicated that the corrosion product consisted primarily of iron and oxygen with minor amounts of silicon and sulfur. Although no microscopic indication of fatigue striations were observed, the fracture features were consistent with progressive failure in high strength steel.

Metallographic specimens were prepared from cross sections of the fracture surface. The fracture surface showed intergranular features with secondary cracks emanating from the fracture surface. The microstructure consisted of tempered martensite with evenly dispersed undissolved carbide particles and manganese sulfide stringers, typical for high strength bearing steel. SEM/EDS analysis confirmed that the dark colored particles were manganese sulfide. Converted ${ }^{3}$ through-thickness microhardness measurements taken on the metallographic specimens averaged 56 Rockwell C scale (HRC), meeting the specified $55 \mathrm{HRC}$ minimum.

Lubricant samples from two different bearing locations and from the tube of unused grease were submitted for analysis. The lubricant from the failed bearing location had been changed during installation of the new bearing, so the sample from this location was a mixture of unused grease and grease at the time of failure. A sample was also taken from cylinder bearing that had not been changed in order to analyze a typical operational sample. A sample of unused grease was taken from the container that was supplied by the technicians who indicated that it was used during bearing maintenance. Both of the used samples were a darker brown color than the unused sample and were heavily contaminated with particles, which degrades the lubricity of the grease.

The samples were analyzed for oxidation with Fourier transformed infrared spectroscopy (FT-IR) and for water content with the Karl Fischer Test. The FT-IR results confirmed that all of the samples were lithium base soap type grease consistent with the composition of the specified grease. The Karl Fischer test results indicated that the grease had absorbed water during service, typical for this type of grease. The unused sample displayed elevated water content above the optimum initial content, which could be due to age and exposure during storage. Qualitative/semi-quantitative SEM/EDS analysis of particles extracted from both of the used grease samples indicated that the grease was contaminated with several metallic and nonmetallic particles. The compositions of the various particles were consistent with corrosion product and environmental contaminants such as sand and rock fragments.

The lubricant analysis indicated severe degradation due to age and contamination with environmental particles. Also, macroscopic indications of misalignment were found on the interior wall of the spherical bearing. The bearing failed in a progressive manner, likely the result of misalignment, with periods of fast crack growth corresponding to cycles of large applied loads. The misalignment could be caused by the failure of the grease to properly transfer the load, leading to the bearing binding in its race.

\section{Failure Due to Design Problems ${ }^{6}$}

During installation of the new launch pad lightning protection towers for the Constellation program, inspectors found toe cracks along a total of nine welds on all three of the towers at various elevations. Cracking occurred along one third or less of the perimeter of each weld between the 10 -in. diameter main horizontal pipe joining two 8-in. diameter bracing pipes, which are shown in Fig. 8. A representative coupon sample was removed from one of the towers at the 101-ft, 3-in. elevation crack area for analysis. Temperature measurements were taken during cutting operations to ensure that the part was not overheated such that no microstructural
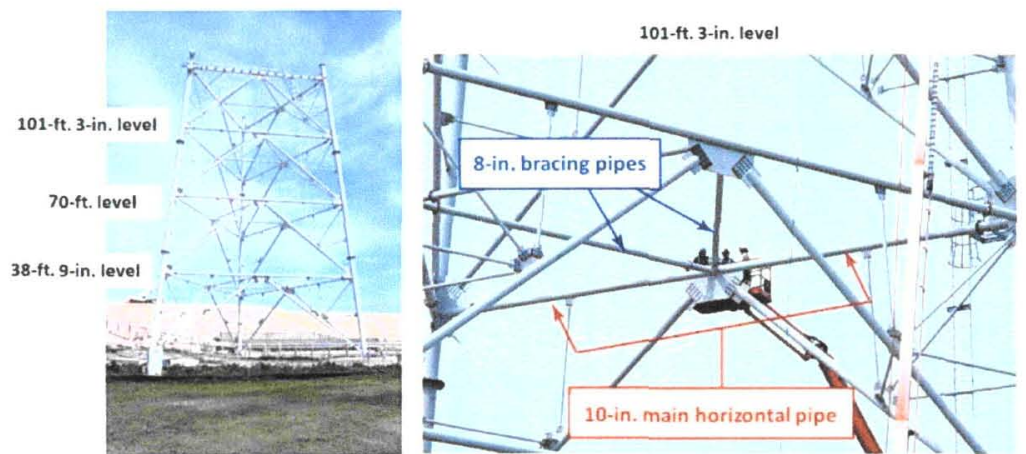

Figure 8. Images of the partially assembled lightning towers at the launch pad.

changes were induced. The pipes were specified as ASTM A 500 Grade B carbon steel. Photodocumentation, stereomicroscopy, SEM analysis, chemical analysis and metallography were performed on three specimens created from the removed coupon to determine the cause of weld toe cracking.

After initial photodocumentation, a sectioning plan was formulated to create cross-sectional samples for stereomicroscopy, metallography, fractography, and chemical analysis. During sectioning of Specimen 1 shown in Fig. 9, the through-crack was exposed to reveal corrosion product on the fracture surface. Specimen 2, which was opened during analysis creating a laboratory-induced overload region, revealed that the crack surface extended to the inner diameter (ID) of the 10-in. pipe and tapered off, as illustrated in Fig. 9, bottom right. No paint was 
observed on the fracture surface, indicating that the crack had initiated after painting and had propagated to its full extent before the coupon was taken, with enough time to allow corrosion product to form.

The fracture surfaces of Specimen 1 were evaluated via SEM at higher magnifications as part of a fractographic analysis. Each surface was ultrasonically cleaned to remove the majority of the corrosion product that had formed on the surface. The fracture surface near the 10-in. pipe outer diameter (OD) contained both intergranular and transgranular crack propagation features with evidence of brittle and ductile (mixed-mode) fracture. Intergranular (IG) crack propagation regions were surrounded by regions of transgranular crack growth. Microvoid coalescence (MVC), indicative of ductile stress overload, was observed near the ID of the pipe.

Further evaluation was performed on the Specimen 2 fracture surface, which exhibited crack propagation demarcations.

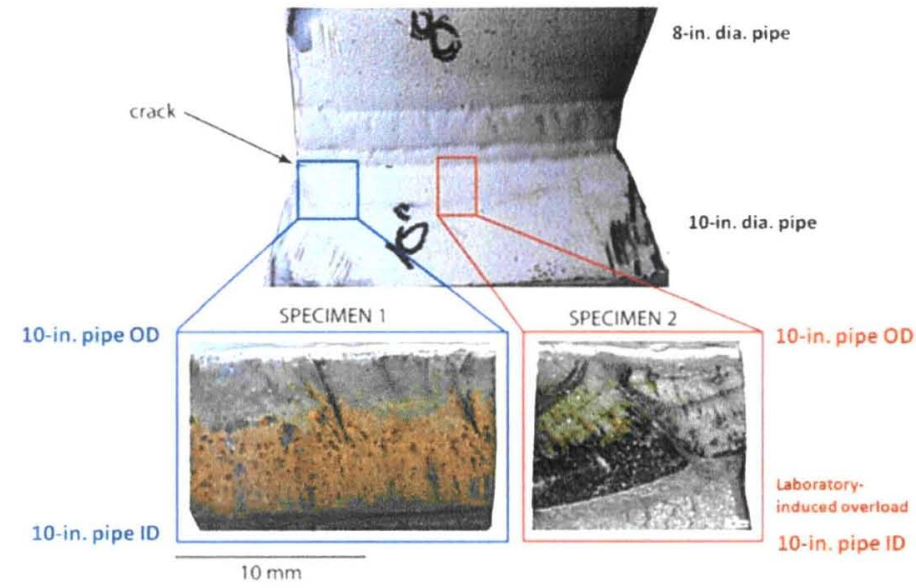

Figure 9. Removed coupon, as received (top), showing the location of the two samples that were opened for fractographic analysis (bottom images). It was determined that the demarcations were not beach marks typically associated with progressive crack growth during fatigue; rather the marks were due to superficial corrosion product build-up on the fracture surface. The secondary electron (SE) image did not show fatigue striations or plastic transgranular deformation normally observed around the site of a beach mark. At higher magnification, SE analysis appeared to show a slight change in fracture features from IG to MVC. Additionally, the backscatter electron (BSE) image exhibited atomic contrast due to the presence of corrosion product forming the curved lines (darker regions) which was verified by energy dispersive spectroscopy (EDS). It is expected that this

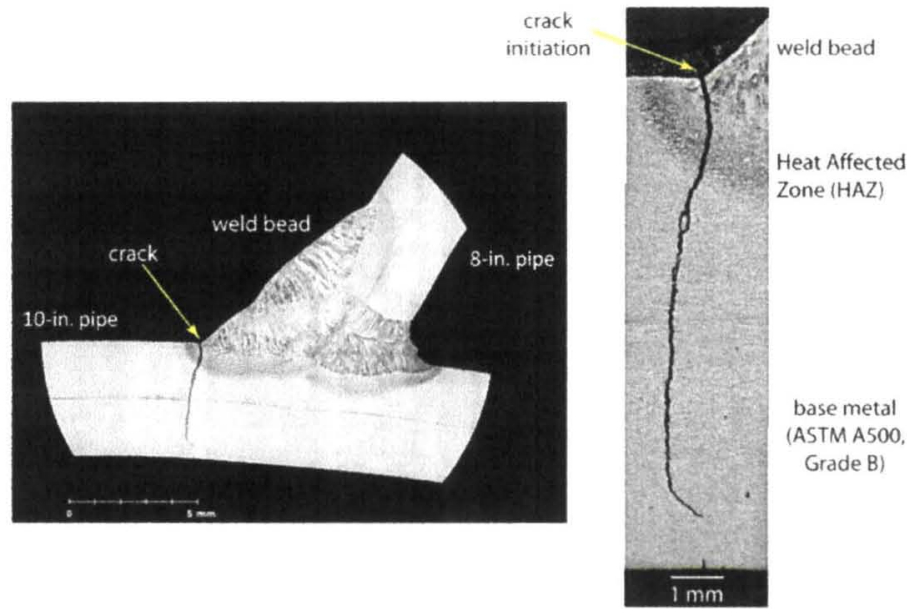

Figure 10. Micrographs of the cross-section of the weld showing the crack at the toe of the weld. failure was due to overload with a geometrical stress state constraint, which prevented the material to plastically deform resulting in a mixed-mode fracture with a large percentage of brittle fracture features. According to the ASM Handbook, Vol. 12, "when a change in the fracture mode does occur as a result of a triaxial state of stress... the mode of rupture can change from the normal dimple rupture to quasi-cleavage or intergranular decohesion."

A third specimen was extracted and a cross section was mounted, polished, and etched to reveal the weld bead, heat affected zone, and base metal microstructure. Metallography showed the crack initiating near the toe of the 10 -in. pipe weld at the joint transition where a stress concentration was expected due to weld geometry, as shown in the left image of Fig. 10. The crack propagated mostly perpendicular to the weld near through-thickness and deviated at a $45^{\circ}$ angle $1 \mathrm{~mm}$ from the ID of the 10 -in. pipe, as shown in the right image of Fig. 10. The cross section exhibited acceptable microstructures for the heat-affected zone (HAZ), weld metal, and base metal as expected for a plain carbon steel fillet weld. Microstructure and crack morphology indicated that this failure was neither due to hydrogen-induced cracking nor other types of materials-related fracture.

Chemical analysis via optical emission spectroscopy indicated that the average carbon content for both the 8-in. pipe and the 10-in. pipe met the specification ${ }^{8}$ and that the chemistry of the pipes was nominal. Microhardness measurements using a Knoop indenter were converted ${ }^{3}$ to the Rockwell B scale (HRB). The converted hardness values indicated that the mechanical properties of the pipes were within the specification ${ }^{8}$. 
The crack profile and fractography indicated that the joint failed due to stress overload. The lack of paint on the fracture surface indicated that the crack occurred after painting. Heavier oxidation on the fracture near the 10-in. pipe ID, rather than the origin at the OD, indicates that moisture had wicked into the fracture and settled over time.

Weld features and geometry appeared nominal. No weld discontinuities or defects were observed. Fracture initiated at a transition near the toe of the weld, a region of stress concentration, and propagated inward through the base metal rather than following the weld HAZ. Microstructure, hardness, and fracture features did not indicate a hydrogen-induced failure mechanism. No other failure mechanisms related to the material were observed.

Loading configuration of this joint design should be evaluated to determine if the joint was overloaded, with the weld toe considered to be a significant point of stress concentration. Future assembly operations should eliminate the possibility of stress overload during fit-up and existing cracks should be repaired.

The reasoning behind the categorization of this failure is more due to the lessons learned from this failure. After completion, the lightning towers stand 500 feet tall with 100 foot high fiberglass masts. The only access to the lightning tower is with a rung ladder on one side of each tower, with four walkways approximately every 125 feet. Routine inspection and maintenance of the towers and the welds, along with troubleshooting of any problems that may arise, will be difficult with the current access configuration, which should be taken into account at the beginning of a new long-term program.

\section{Conclusion - The Role of Age in Failure at KSC}

One factor that plays a role in every failure analysis and is one of the first questions asked in the course of an investigation is the age of the component. The failure of a new part may indicate a problem with the design or fabrication of a component. The failure of a part that is 20 years or older may signify a problem with maintenance. In several cases, age itself can be the cause of the failure; for example in many cases where fatigue or corrosion is the failure mechanism, only routine inspection and replacement can mitigate these failures prior to larger system failure.

A survey of jobs performed over the past three years by the NASA Materials Failure Analysis section was completed in order to determine the distribution of component age at failure. So far, over 50 failure analysis cases have been reviewed, and the distribution of component age is shown in Fig. 11. For some of the ground support equipment at $\mathrm{KSC}$, documentation of the age is not available, especially when the component has been in service for over 20 years. These cases have not been incorporated into the distribution at this time in order to perform further research to determine the age of the components.

Over the past three years, the Materials Failure Analysis section has performed failure analysis for components with an average service life of 17.5 years for cases where the age of the component was known and that the component was not new (less than 3 months old). Over one third of the failure analysis cases are for new hardware and over one third of the failure analysis cases are for hardware that is over 20 years old. At this time a true statistical distribution of the component age at failure cannot be determined until further data are collected over a greater time period, which will be completed in a future study. However, the expected distribution of failure age is close to a bimodal distribution with the preponderance of failures occurring either at the beginning of the life-cycle due to design or fabrication problems, or many years later when the component becomes susceptible to age-related failures.

In spite of the limitations of the current survey, the results have implications for the present state of work at KSC. The Shuttle program has been in operation for almost 30 years, and the age of the hardware and ground support equipment is at one of the peaks for failure. As the Shuttle program concludes and new programs begin at $\mathrm{KSC}$, the need for failure analysis is at its most critical point on two fronts. With vigilant failure analysis, NASA can obviate failure and continue flying safely. 


\section{Acknowledgments}

The authors acknowledge the work of all of the contributors in the NASA KSC Materials Science Division who performed work for the case studies: Larry Batterson, Glenn Bean, Chad Carl, Debbie Folmar, Philip Howard, Dionne Jackson, Dr. Hae Soo Kim, Roy King, Dean Lewis, Dr. Kathleen Loftin, Sandra Loucks, Greg Melton, Scott Murray, Jeffrey Sampson, and Peter Richiuso. The authors thank the members of the Materials Failure Analysis Laboratory, both past and present, for their contribution to this work: Steve McDanels, David Lubas, Patrick Faughnan, Peter Marciniak, Donald Parker, Bryan Tucker, and Jennie Ward. Special thanks to Dr. Christopher Long and Dawson Wright. The authors thank the management team of the Materials Science Division for the support in this endeavor: Division Chief Scott Murray, Foster Anthony, and Angela Balles.

\section{References}

'Coburn, S., "Atmospheric Corrosion," Metals Handbook, 9th ed., Vol. 1, Properties and Selection, Carbon Steels, American Society for Metals, Metals Park, Ohio, 1978, p.720.

${ }^{2}$ Salazar, V.L., "Suspect Crack Indications in Payload Canister Trunnion Support Fittings," Report KSC-MSL2006-0409, 2006.

${ }^{3}$ ASTM Standard E 140, "Standard Hardness Conversion Tables for Metals Relationship among Brinell Hardness, Vickers Hardness, Rockwell Hardness, Superficial Hardness, Knoop Hardness, and Scleroscope Hardness," ASTM International, West Conshohocken, PA, 2003, DOI: 10.1520/E0140-07, www.astm.org.

${ }^{4}$ Salazar, V.L., "Analysis of Wire Rope from Launch Complexes (LC) 39A and 39B," Report KSC-MSL-2009$0081,2009$.

${ }^{5}$ Salazar, V.L., "Failure Analysis of a Spherical Bearing from Crawler/Transporter 1 (CT-1) D-2 Steering Cylinder," Report KSC-MSL-2005-0215, 2005.

${ }^{6}$ Wright, M.C., "Failure Analysis of Cracking along Welds on the Launch Complex (LC) 39B Constellation Lightning Protection Towers," Report KSC-MSL-2008-0431, 2008.

${ }^{7}$ Kerlins, V. and Phillips, A., "Modes of Fracture," ASM Handbook Vol. 12 Fractography, Ninth edition, ASM International, Metals Park, OH, 1987.

${ }^{8}$ ASTM Standard A 500/500M, "Standard Specification for Cold-Formed Welded and Seamless Carbon Steel Structural Tubing in Rounds and Shapes," ASTM International, West Conshohocken, PA, 2009, DOI: 10.1520/A0500_A0500M-09, www.astm.org. 


\title{
Failure Analysis at the Kennedy Space Center
}

\author{
V.L. Salazar and M.C. Wright
}

National Aeronautics and Space Administration

Kennedy Space Center, FL

\section{Introduction}

- Failures can occur in every engineering endeavor, and what we learn from those failures contributes to the knowledge base to safely complete future missions.

- The necessity of failure analysis is at its apex at the end of one aged program and at the beginning of a new and untested program.

- The information that we gain through failure analysis corrects the deficiencies in the current vehicle to make the next generation of vehicles more efficient and safe. 


\section{Types of Failure}

- The Failure Analysis and Materials Evaluation Branch in the Materials Science Division at the Kennedy Space Center.

- Metallurgical, mechanical, electrical, and non-metallic materials failure analyses and accident investigations.

- Flight hardware and ground support equipment for the Shuttle, International Space Station, Constellation, and Launch Services Programs.

- The majority of failures can typically be attributed to one or more of the following causes.

- Failure due to fabrication problems.

- Failure due to environmental problems.

- Failure due to maintenance problems.

- Failure due to design problems.

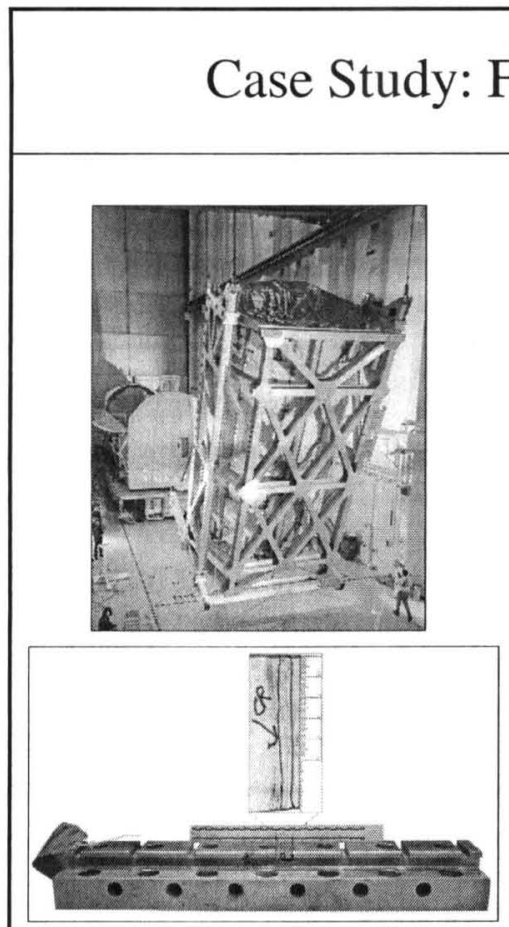

- The Rotation Handling Fixture is used to lift the modules of the ISS into a vacuum chamber in order to perform leak checks.

- A payload canister rail from the Rotation Handling Fixture was submitted for failure analysis when a crack was observed on the top of the rail during installation ${ }^{1}$.

- The rail was specified as AISI 4140 steel. 


\section{Case Study: Failure due to Fabrication}

- The failure surfaces were flat and only had small regions of fracture around the edge of the surface.

- Plating was observed on one of the surfaces.

- The other surface displayed tools marks that appeared to be the result of a machining and grinding operation.

- Metallographic specimens were prepared from cross sections of the rail.

- A piece of metal was welded into a notch cut in the base material.

- The fill material was determined to be a 1000 -series steel.

- The size of the fill material was the same size as machined notches that were located

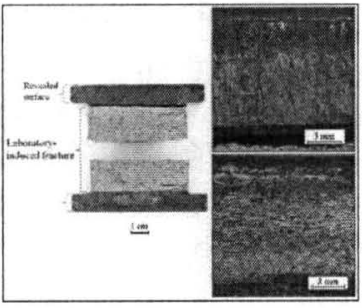
in six positions on the rail.

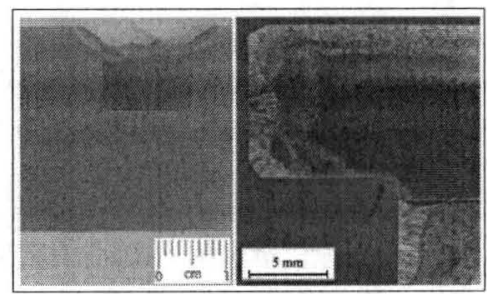

\section{Case Study: Failure due to Fabrication}

- The payload canister rail failed due to improper fabrication techniques.

- Six cut notches were located on the rail, which were intended for installation of the thrust block used to secure the payload to the rail.

- The rail had two cut notches that were not in accordance with the drawing, and were then filled with a low-strength, 1000 -series steel and welded into place.

- The rail subsequently cracked due to stress overload. 


\section{Case Study: Failure due to Environment}

- Sections of wire rope from the lightning protection system at the launch pads were submitted for inspection to determine potential future usage of similar wire rope ${ }^{2}$.

- Wire rope was type 316 stainless steel.

- Installed in 2001 and removed in 2008.

- Visual observation of the wire rope revealed damage that was due to two separate environmental problems: corrosion and possible lightning damage.

${ }^{2}$ Salazar, V.L., "Analysis of Wire Rope from Launch Complexes (LC) 39A and 39B," Report KSC-MSL-2009-0081, 2009

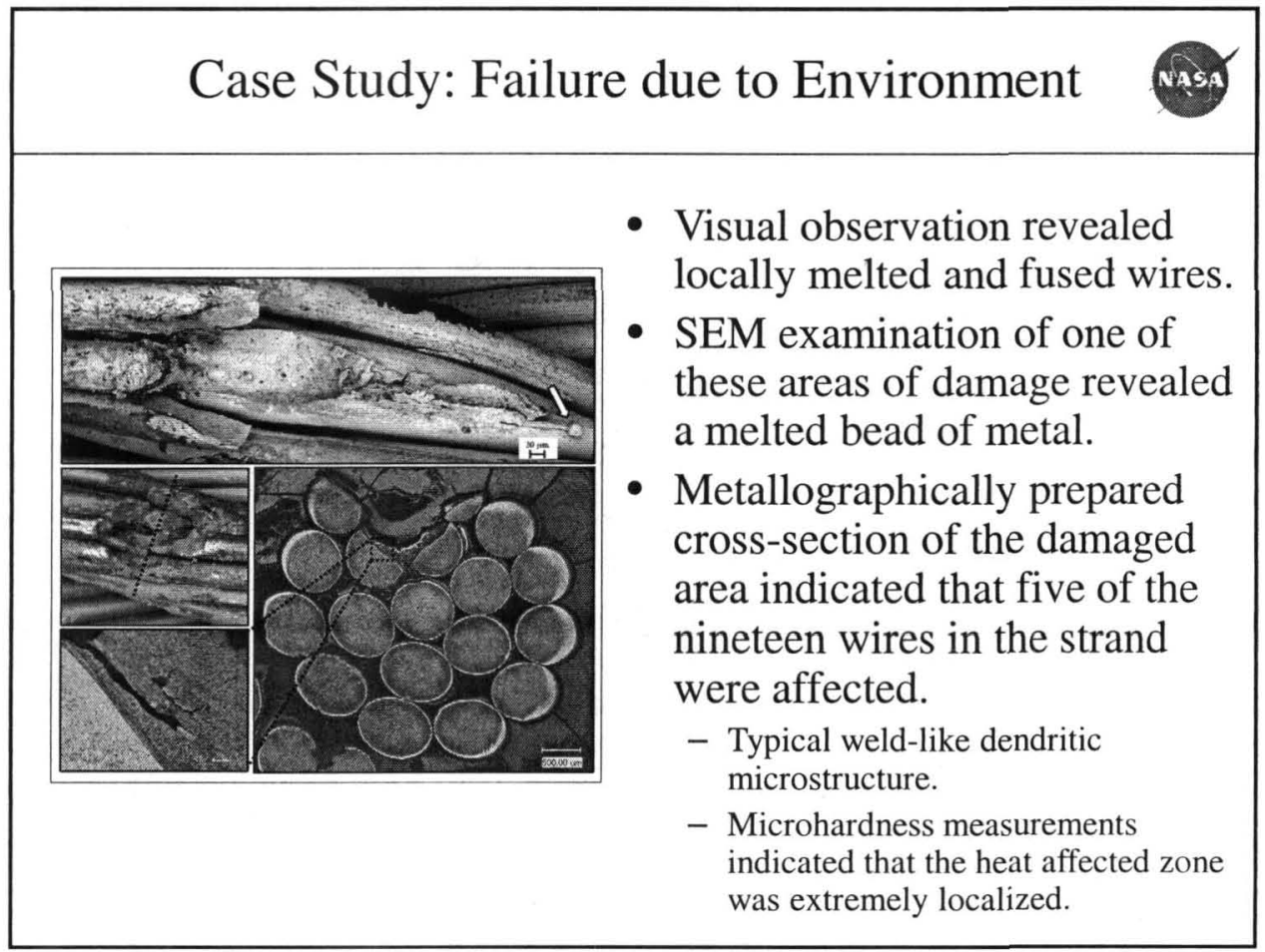




\section{Case Study: Failure due to Environment}

- Stereomicroscopic inspection of one of the ropes revealed pitting of approximately one quarter of the wires in one of the strands of the wire rope cross-section.

- The morphology and composition of deposits observed within the pit via SEM/EDS were typical of solid rocket booster (SRB) combustion product deposit.

- Approximately two-thirds of the interior portion of the cross-section was removed.

- Grain boundary attack caused the wormhole-like pitting of the interior of the wire since the corrosion mechanism

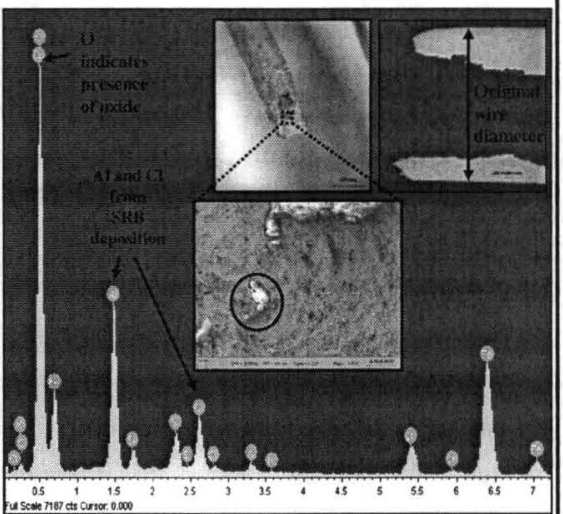
acted longitudinally with the grain structure.

\section{Failure due to Maintenance}

- The crawler transporter is used to move the shuttle transportation system to the launch pad after mating operations in the Vehicle Assembly Building (VAB).

- A spherical bearing from a steering cylinder of the crawler transporter (CT) was submitted for failure analysis when a crack was observed during maintenance ${ }^{3}$.

- The spherical bearing was composed of AISI E52100 bearing steel (UNS G52986).
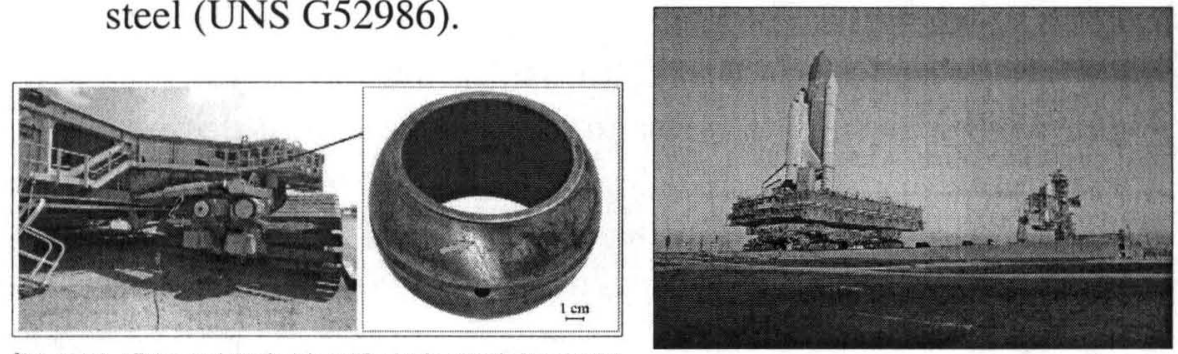

${ }^{3}$ Salazar, V.L. "Failure Analysis of a Spherical Bearing from Crawler/Transporter (CT-1) D-2 Steering Cylinder," Report KSC-MSL-2005-0215, 2005. 


\section{Failure due to Maintenance}

- The cleaned fracture surface displayed conchoidal crack-arrest lines that indicated progressive failure.

- No microscopic indication of fatigue striations were observed via SEM; however, the fracture features were consistent with progressive failure in high strength steel.

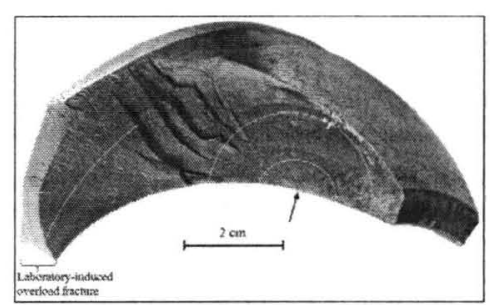

- Samples of used and unused lubricant were taken for analysis.

- The used samples were a darker brown color than the unused sample and were heavily contaminated with environmental particles (e.g., rock, sand).

- Analysis of the samples using Fourier transformed infrared spectroscopy (FT-IR) indicated that the used samples were oxidized.

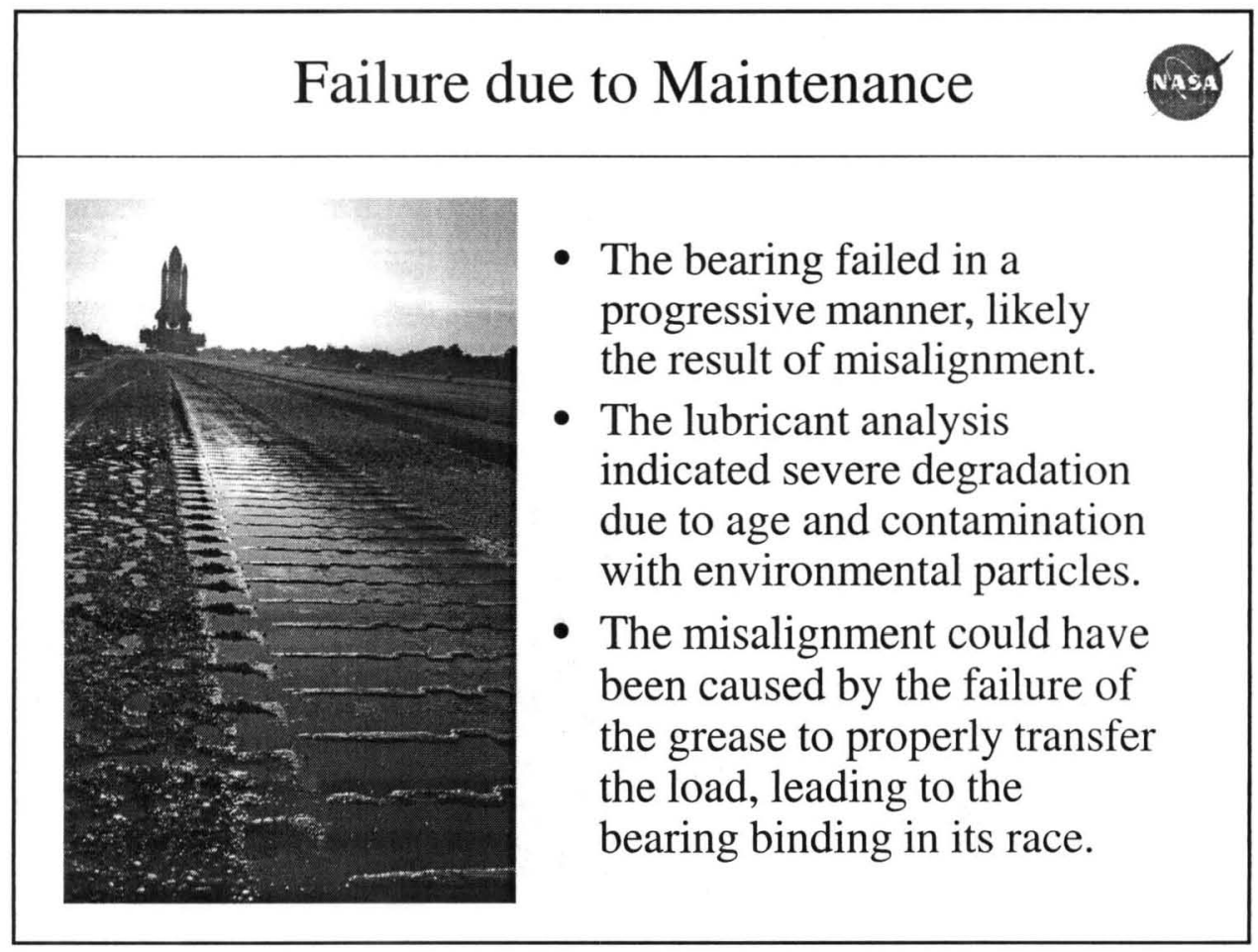




\section{Failure due to Design}

- During installation of the new launch pad lightning protection towers for the Constellation program, inspectors found toe cracks along a total of nine welds on all three of the towers at various elevations ${ }^{4}$.

- The pipes were specified as ASTM A 500, Grade B, carbon steel ${ }^{5}$.

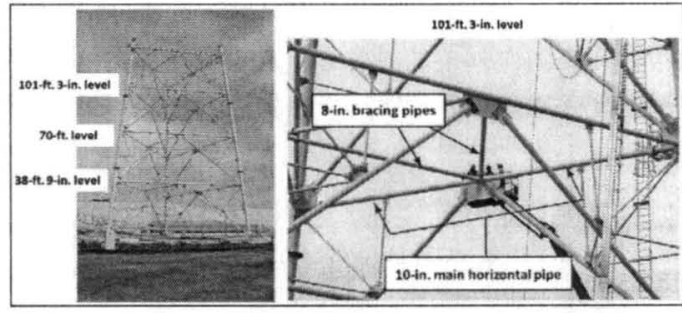

sWright, M.C., "Failure Analysis of Cracking along Welds on the Launch Complex (LC) 39B Constellation Lightning Protection Towers." Report KSC-MSL 2008-0431. 2008. "ASTM Standard A 500/500M, "Standard Specification for Cold-Formed Welded and Seamless Carbon Steel Structural Tubing in Rounds and Shapes," ASTM International, West Conshohocken. PA, 2009, DOE 101520/A0500 A0500M-09, www astmorg.

\section{Failure due to Design}

- Demarcations observed on the fracture surface were not beach marks typically associated with fatigue; rather the marks were due to superficial corrosion product build-up on the fracture surface, as determined with SEM/EDS.

- Failure was due to overload with a geometrical stress state constraint, which prevented the material to plastically deform.

- The crack initiated near the toe of the 10-in. pipe weld at the joint transition where a stress concentration was expected due to weld geometry.
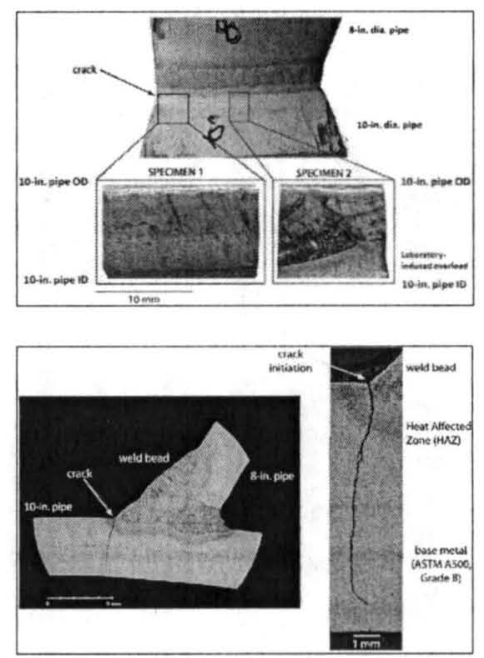


\section{Failure due to Design}

- The crack profile and fractography indicated that the joint failed due to stress overload during fit-up.

- The reasoning behind the categorization of this failure is due to the lessons learned from this failure.

- The lightning towers stand 500 feet tall with 100 foot high fiberglass masts.

- Access to the lightning tower is with a rung ladder, with four walkways approximately every 125 feet.

- Routine inspection and maintenance of the towers, along with troubleshooting of any problems that may arise, will be difficult with the current access configuration.

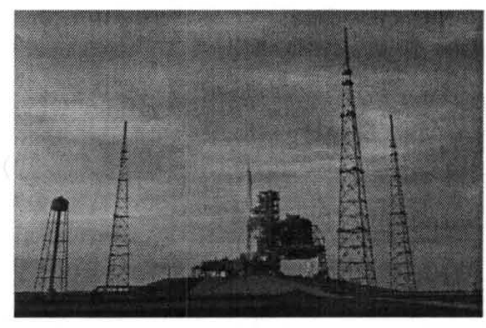

\section{The Role of Age in Failure}

- One factor that plays a role in every failure analysis, and one of the first questions asked in the course of an investigation, is the age of the component.

- The age of the part can aid in the determination of the cause of failure.

- A survey of jobs was performed for the past three years by the NASA Materials Failure Analysis section.

- Average service life of 17.5 years.

- Over one third of the failure analysis cases are for new hardware and over one third of the failure analysis cases are for hardware that is over 20 years old.

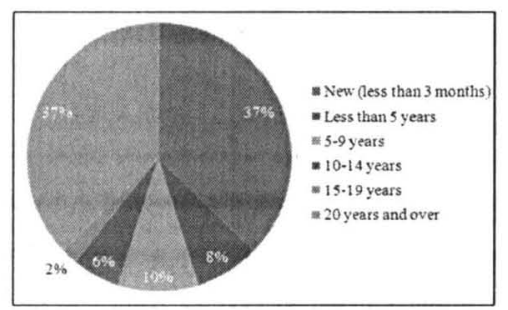




\section{Conclusion}

- The results have implications for the present state of work at KSC.

- The Shuttle program has been in operation for almost 30 years, and the age of the hardware and ground support equipment is at one of the peaks for failure.

- As the Shuttle program concludes and new programs begin at KSC, the need for failure analysis is at its most critical point on two fronts.

- With vigilant failure analysis, NASA can obviate failure and continue flying safely.

\section{Acknowledgements}

The authors acknowledge the work of all of the contributors in the NASA KSC Materials Science Division who performed work for the case studies: Larry Batterson, Glenn Bean, Chad Carl, Debbie Folmar, Philip Howard, Dionne Jackson, Dr. Hae Soo Kim, Roy King, Dean Lewis, Dr. Kathleen Loftin, Sandra Loucks, Greg Melton, Scott Murray, Jeffrey Sampson, and Peter Richiuso. The authors thank the members of the Materials Failure Analysis Laboratory, both past and present, for their contribution to this work: Steve McDanels, David Lubas, Patrick Faughnan, Peter Marciniak, Donald Parker, Bryan Tucker, and Jennie Ward. Special thanks to Dr. Christopher Long and Dawson Wright. The authors thank the management team of the Materials Science Division for the support in this endeavor: Division Chief Scott Murray, Foster Anthony, and Angela Balles. 


\section{Failure Analysis at the Kennedy Space Center}

National Aeronautics and Space Administration, Kennedy Space Center, FL

4

2.8.

INTRODUCTION

History has shown that fallures can occur in every enginecring endeavor, and what we learn from
oose failures contributes to the knowidedec base to safely complete futurere missions. The information that we

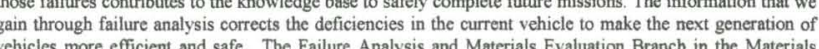
Science Division at the Kennedy Space Center performs metallurgical, mechanical, electrical, and noor

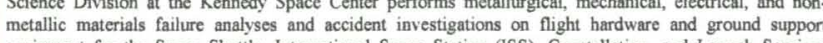
equipment for the Space Shuttie, International Space Station (ISS), Constellation, and Launch Services

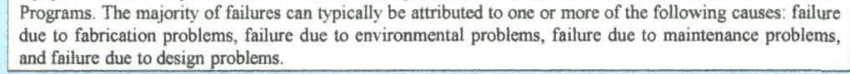

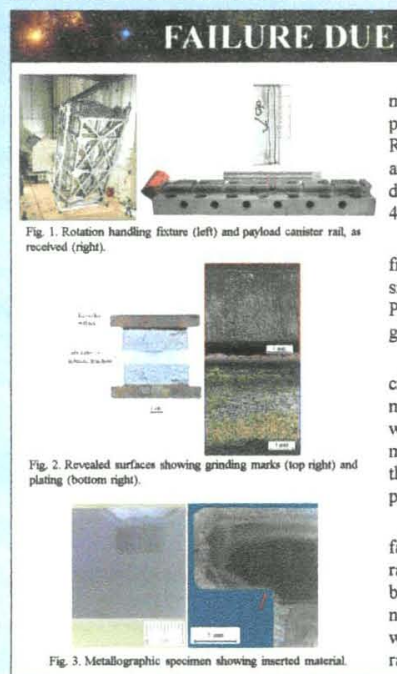

The Rotation Handling Fixture is used to lif the
modules of the ISS into a vacuum chamber in ordec to perform leak checks. A payload canister rail from the Rotation Handling Fixture was submitted for fallurc

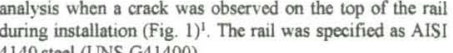
The crack was opened in order to examine the
fracture surface (Fig. 2). The surfaces were flat and had a mall region of fracture around the edge of the surface Fating was observed on one of the revealed surfaces and Metallographic specimens were prepared from

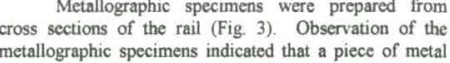
was werded into a notch cut in the base material. The fill material was determined to be 1000 -series stece, and was
the same size as machined notches hhat werc located in six ins on the rail

The payload canister rail failed due to improper
fabriction techniques. Six cut notches were located on the rail, which were intended for installation of the thrust
block used to secure the pavload. The rail had two cut

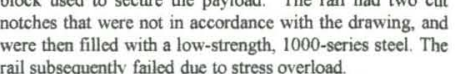

\section{* * FAILURE DUE TO ENVIRONMENT} Sections of wire rope from the lighthing protection system at the launch pads were submited for

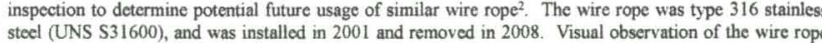
revealed damage due to two separate envirommental problems. corrosion and possible lightning damage. Damage due to lighthing

Several areas of damage werc observed on the surface of the
wire rope that were locally melted and fused wires (Fig. 4). SEM oxamination of one of these arcas of damage revealed a melted bced

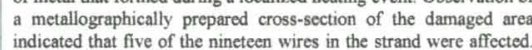
The damaged arca had a typical weld-like dendritic microstructure

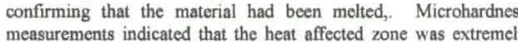
measurem
localized.
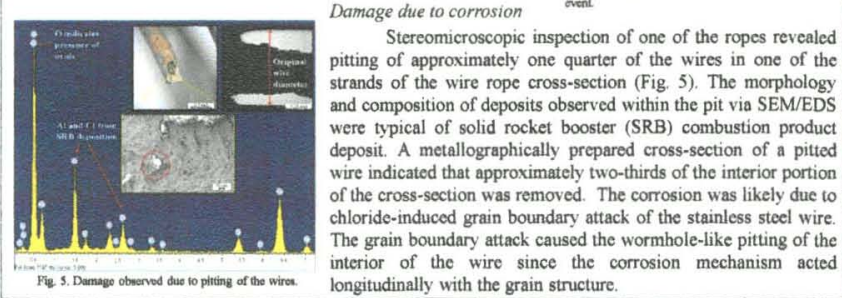

* Fallure due to MaINTENANCE

The cravier transporter is used to move the shutle to
the launch pad after manting operations in the Vehicle Assembly
Buid diog (VAB)

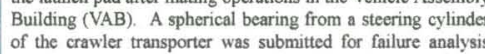

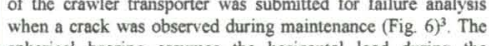
spherical bearing assumes the horizontal liad during
steering of one of the four individual truck assemblies bearin was composed of AISI ES2100 bearing steel (UNS
G52086) The revealed fracture surface was coated with grease
and had a bunth odor when it was popened-evidence that the

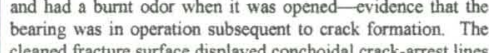

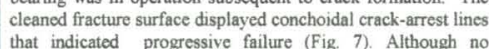
that indicated progressive failure (Fig. 7). Athough no
microscopici indication of fatigue striations was observed, the

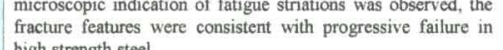

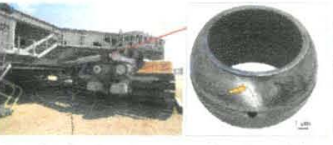

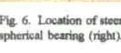

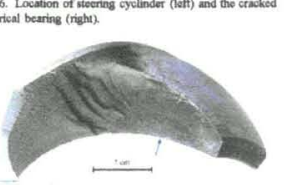
Samples of used and unused lubricant werc taken for
analysis. The used samples were a darker brown color han the unused sample and were heavily contaminiated with particls

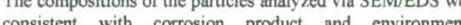
grease samples using Fourier transformed inffared
spectroscopy nidicated hat he thed samples were oxdired.

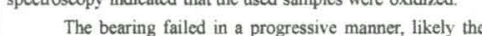
The bearing failed in a progressive manner, likely the
result of misaligmment. The lubricant analysis indicated severe

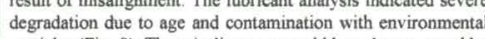
particles (Fig. 8). The misalignment could have been caused by the falitre of the grease to property transfer the load, leading to
the bearing binding in its race.

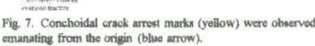

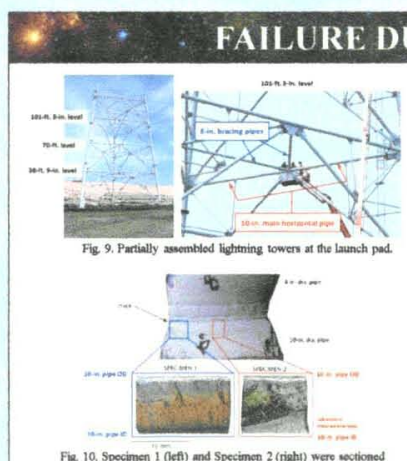

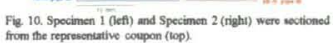

A cross section from the coupon was prepared for
metallographic examinantion (Fig II) The crack initines near the toc of the 10 -in pipe weld at the joint transitiog where a stress concentration was expected due to well geometry. The microstnucture of the weld and base meta
was typical for a plain carbon steel fillet weld

The crack profile and fractography indicated that the
joint failed due to stress overload during fit-up the reasoning behind the categorization of this failure is due the lessons learned from this failure. The lightring towers stand 500 feet tall with 100 foot high fiberglass masts (Fis approximately every 125 feet. Routine inspection and maintenance of the towers and the welds, along with
troubleshooting of any problems that may arise, will be troubleshooting of any problems that may arts.
difficult with the currout access configuration.

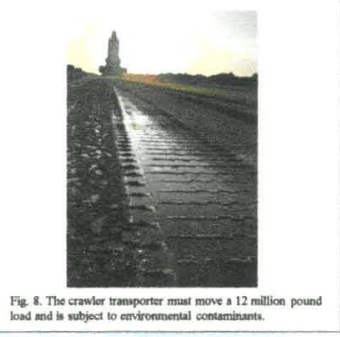

During installation of the new launch pad

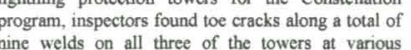

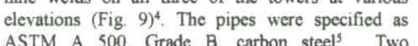
specimens were sectioned from a representative
coupon removed from one of the towers (Fig. 10 ). SEM xeamination of the Specimen 1 fracture
surface revecaled evidence of britle and ductile surface revealed evidence of of nitile and ductil
mixed-mode) fracture. Demarcations observed on he Specimen 2 fracture surface were not beach
narars typically associated with fatigue, rather the

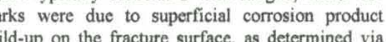
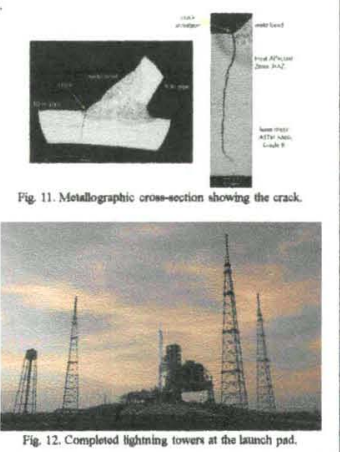

* CONCLUSION-THE ROLE OFAGE

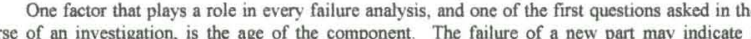
problem with the design or fabrication of $\mathrm{a}$ component. The falulure of a part hat is 20 years or or older

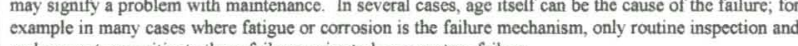
larger system failue

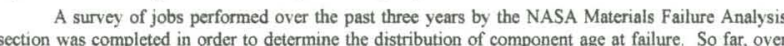
50 fallure analysis cases have been reviewed. For some of the ground support equipment at KSC.

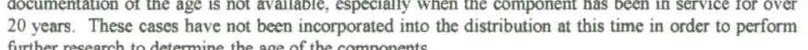
detemine the age of the components

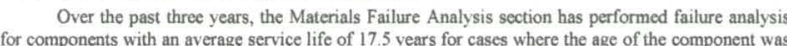
known and that the component was not new (less than 3 months old). Over one third of the failure analysis cases are for new har
that is over 20 years old (fig 1 )

The results have implications for the present state of work at KSC. The Shutle program has we of the peaks for failuse 30 years, and the age of the hardware and ground support equipment is iced for rallure analyssis is at it its most critical point on two fronts. With vigilant fallure analysis, NASA can obviate failure and continue flying safelts

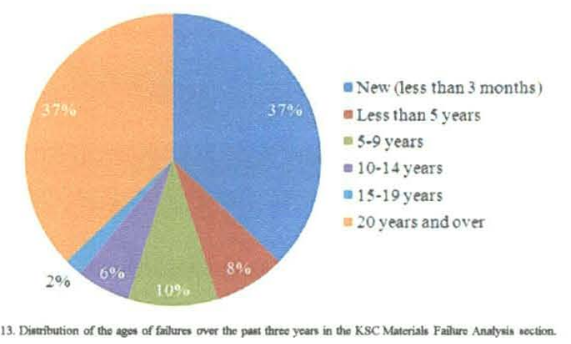

\section{- ACKNOWLEDGMENTS}

The authors acknowledge the work of all of the contributors in the NASA KSC Material Debbie Folmar, Philip Howard, Dionne Jackson, Dr. Hae Soo Kim, Roy King, Dean Lewis, Dit

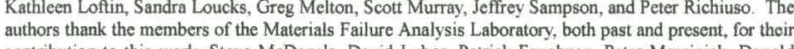

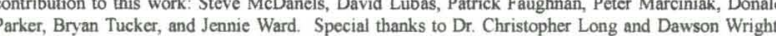
The authors thank the management teamo of the Materials Science Division for the support in this ndeavor: Division Chief Scott Murray, Foster Anthony, and Angela Balls

\section{* * REFERENCES}

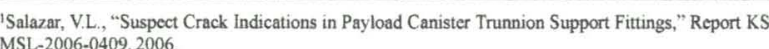

2Salazar, V.L, "Analysis of Wire Rope from Launch Complexes (LC) 39A and 39B;" Repport KSC.
MSL-2009-0081,2009. 3Salazar, V.L., "Failure Analysis of a Spherical Bearing from Crawler/Transporter 1 (CT-1) D-2
Stecring Cyinder," Report KSC-MSL-2005-0215, 2005.

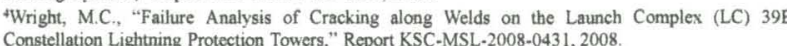

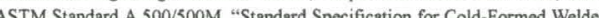

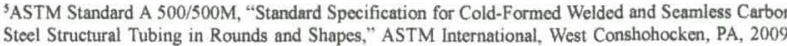

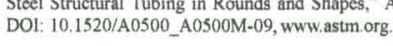

